Pacific Journal of Mathematics

SUBSPACE KERNELS AND MINIMUM PROBLEMS IN
HILBERT SPACES WITH KERNEL FUNCTION 


\title{
SUBSPACE KERNELS AND MINIMUM PROBLEMS IN HILBERT SPACES WITH KERNEL FUNCTION
}

\author{
Bruce L. Chalmers
}

\begin{abstract}
The purpose of this paper is to extend the theory of Hilbert spaces with kernel function to obtain first the kernel function of any subspace described as the intersection of the nullspaces of countably many continuous linear functionals, and secondly the solution of minimum norm to interpolation problems involving countably many linear side conditions. The results are then applied to obtain in $\S 1$ a class of pseudoconformally invariant functions in $C^{n}$ and in $\S 2$ further results on the classical interpolation problem involving pointwise evaluation.
\end{abstract}

Any closed subspace of a Hilbert space with (reproducing) kernel function has itself a reproducing kernel. In $\S 1$ (see also [8]) it is shown that the Riesz representation of any bounded linear functional in a Hilbert space with kernel function is obtained by operating with the linear functional on the kernel function itself (see Theorem 1.1). Using this representation, one can display, in terms of the kernel function of the original space, the kernel function of any closed subspace defined as the intersection of the null spaces of at most countably many bounded linear functionals (see Theorems 1.2 and 1.3). By applying this representation to the Bergman space $H_{B}^{n}$ of all analytic square integrable functions defined on a domain $B \subset C^{n}$, one obtains a large class of pseudoconformally invariant functions (see Theorem 1.7 and Note 1.8). As an example are obtained important invariant functions introduced and used by Bergman ([2]-[6]) and others (e.g., [13]).

The solution of minimum problems of the type requiring the infimum of the norm of functions under a finite number of bounded linear side conditions in Hilbert space with kernel function was obtained in [7], by use of the Riesz representation of Theorem 1.1. In $\S 2$ of this paper is obtained a necessary and sufficient condition for the existence of the solution to such minimum problems under countably many bounded linear side conditions. When the solution exists, it can be displayed in terms of the kernel function again by use of the Riesz representation of Theorem 1.1 (see Theorem 2.1 and Corollary 2.2). Applying these results one obtains necessary and sufficient conditions for the existence of solutions to a large family of interpolation problems, examples of which are given in the spaces $H_{[|z|<1]}^{n}$ and the Hardy space $H_{2}[|z|<1]$ (see Corollary 2.3-Corollary 2.8). 
1. Kernel functions of subspaces. Let $H$ denote a general Hilbert space with inner product denoted by $(f, g)$ and norm $\|f\|=$ $(f, f)^{1 / 2}$ where $f, g \in H$. Let $H^{\circ}$ denote the space of all bounded linear functionals on $H$. If $\mathscr{L} \in H^{\circ}$ has the Riesz representation $L \in H$, we denote this correspondence by $\mathscr{L} \sim L$.

Suppose further that $H$ is a Hilbert space of functions $\{f(x)\}$ defined on a base set $E$ and that $H$ has a (reproducing) kernel function $K(x, y)$. Then we denote such a Hilbert space by $H K$ or $H K(E)$.

For fixed $y$ the kernel function $K(x, y)$ is the function providing the Riesz representation in $H K$ of the bounded linear functional $\mathscr{L} \in H K^{\circ}$ given by $\mathscr{L}(f)=f(y)$ for $f \in H K$. The following theorem (see [8]) shows that not only pointwise evaluation but all bounded linear functionals on $H K$ have a simple representation in $H K$ in terms of the kernel function $K(x, y)$. In fact the representation is obtained by simply applying such a functional to $K(x, y)$ itself:

Theorem 1.1. If $\mathscr{L} \in H K^{\circ}$, then $\mathscr{L} \sim L(x)=\overline{\mathscr{L}_{y}(K(y, x))}$. (Here the $y$ subscript emphasizes that $\mathscr{L}$ is operating on $K(y, x)$ in $H K$ as a function of $y$.)

$$
\text { Proof. } L(x)=(L(y), K(y, x))=\left(\overline{K(y, x), L(y))}=\overline{\mathscr{L}_{y}(K(y, x))} .\right.
$$

ExAMPLE. In the case of evaluation of the derivative at $z$ in $H_{B}^{1}, \mathscr{L}: f \rightarrow f^{\prime}(z)$, then

$$
\overline{\mathscr{L}_{y}(K(y, \bar{x}))}=\left.\frac{\overline{\partial K(y, \bar{x})}}{\partial y}\right|_{y=z}=\left.\frac{\partial K(x, \bar{y})}{\partial \bar{y}}\right|_{y=z} .
$$

Notation. Suppose $\mathscr{L}^{m} \in H^{\circ}, m=1,2, \cdots, n$ are linearly independent and that $\mathscr{L}^{m} \sim L_{m}, m=1,2, \cdots, n$. Then denote by $D$ the determinant of the $n \times n$ matrix $Q=\left\{\overline{\left(L_{k}, L_{m}\right)}\right\}_{n \times n}$. Denote by $D_{w}^{v}(R)$ the determinant of the $(n+1) \times(n+1)$ matrix $\left(\begin{array}{ll}R & v \\ w & Q\end{array}\right)$, where $v=\left(v_{1}, \cdots, v_{n}\right)$ is a row vector and $w=\left(w_{1}, \cdots, w_{n}\right)^{T}$ is a column vector. Note also that in the case of $\left.H K,\left(L_{k}, L_{m}\right)=\mathscr{L}_{x}^{m}\left(\overline{\mathscr{L}_{y}^{k}(K(y, x)}\right)\right)$.

TheOREM 1.2. Suppose $\mathscr{L}^{m} \in H K^{\circ}, m=1,2, \cdots, n$ are linearly independent. Then, letting $\mathscr{L}(t)=\left(\mathscr{L}_{z}^{1} K(z, t), \cdots, \mathscr{L}_{z}^{n} K(z, t)\right)$, we have that $\overline{D_{\mathscr{C}(y)}^{(x)}}(K(x, y)) / D$ is the kernel function $k_{n}(x, y)$ of the subspace $H_{n}=\left\{f \in H K ; \mathscr{L}^{r} f=0, r=1, \cdots, n\right\}$.

Proof. Let $k_{n}^{*}(x, y)=D_{\mathscr{S}(y)}^{\overline{F^{(x)}}}(K(x, y)) / D$. For each fixed $y, k_{n}^{*}$ equals $K(x, y)+\sum_{r=1}^{n} c_{r} \overline{\mathscr{L}_{z}^{r} K(z, x)}$ for some constants $c_{1}, \cdots, c_{n}$ and 
thus belongs to $H K$. For each $r, \mathscr{L}_{x}^{r} k_{n}^{*}(x, y)=0$, since

$$
\mathscr{L}_{x}^{r}\left(D_{\mathscr{L}(y)}^{\overline{F^{(x)}}}(K(x, y))\right)
$$

is a determinant of a matrix with the $1^{\text {st }}$ and $r^{\text {th }}$ rows equal. Finally if $f \in H_{n}$, then $\left(f(x), k_{n}^{*}(x, y)\right)=f(y)+\sum_{r=1}^{n} c_{r} \mathcal{P}^{r} f=f(y)$. So $k_{n}^{*}(x, y) \equiv k_{n}(x, y)$.

THeOREM 1.3. Suppose $\mathscr{L}^{m} \in H K^{\circ}, m=1,2, \cdots$ are linearly independent. Let $k_{n}(x, y)$ denote the kernel function of the subspace $H_{n}=\left\{f \in H K ; \mathscr{L}^{r} f=0, \quad r=1, \cdots, n\right\}$. Then $\lim _{n \rightarrow \infty} k_{n}(x, y)$ gives the kernel function $k(x, y)$ of the subspace $H_{\infty}=\left\{f \in H K ; \mathscr{L}^{r} f=0\right.$, $r=1,2, \cdots\}$, where in each variable the convergence is both in the norm and pointwise uniform on each set $E^{1}$ on which $K(z, z)$ is bounded.

Proof. Let $\mathscr{L}^{r} \sim L_{r}, r=1,2, \cdots$. If $S$ is the subspace of $H K$ spanned by the $\left\{L_{r}\right\}$, then $S$ is the orthogonal complement of $H_{\infty}$ in $H K$. Now orthogonalize $\left\{L_{1}, L_{2}, \cdots\right\}$ by the Gram-Schmidt process to get $\left\{M_{1}, M_{2}, \cdots\right\}$. Thus $K(x, y)=k(x, y)+\sum_{r=1}^{\infty} M_{r}(x) \overline{M_{r}(y)}$, and $k_{n}(x, y)=k(x, y)+\sum_{r=n+1}^{\infty} M_{r}(x) M_{r}(y)$, as is easily checked. Thus,

$$
\begin{aligned}
& \left\|k_{n}(x, y)-k(x, y)\right\|^{2}=\left\|k_{n}(x, y)\right\|^{2}-\left(k_{n}(x, y), k(x, y)\right) \\
& -\left(k(x, y), k_{n}(x, y)\right)+\|k(x, y)\|^{2}=k_{n}(y, y)-k(y, y) \\
= & \sum_{r=n+1}^{\infty}\left|M_{r}(y)\right|^{2} \rightarrow 0
\end{aligned}
$$

for each fixed $y \in E$. Furthermore, we have

$$
\begin{aligned}
\left|k_{n}(x, y)-k(x, y)\right|^{2} & =\left|\left(k_{n}(z, y)-k(z, y), K(z, x)\right)\right|^{2} \\
& \leqq\|K(z, x)\|^{2}\left\|k_{n}(z, y)-k(z, y)\right\|^{2} \\
& =K(x, x)\left[k_{n}(y, y)-k(y, y)\right] .
\end{aligned}
$$

Hence for $y$ fixed $k_{n}(x, y) \rightarrow k(x, y)$ pointwise uniformly on each set $E^{1}$ on which $K(z, z)$ is bounded. Since

$$
\overline{k_{n}(x, y)-k(x, y)}=k_{n}(y, x)-k(y, x),
$$

the same statements hold for fixed $x$.

Note 1.4. If $H K$ is separable then any closed subspace of $H K$ is of the form $H_{\infty}$ in Theorem 1.3.

ExAMPle 1.5. If $B$ is a bounded domain in $C^{n}$, let

$$
K=K_{B\left(u_{r}, m\right)}(z, \bar{w})
$$


denote the kernel function of $H_{B}^{n} \cap\left[f_{r^{\nu}}\left(u^{\nu}\right)=0, u^{\nu} \in B, \nu=1,2, \cdots, m\right]$, where

$$
f_{r^{\nu}}(z)=\frac{\partial^{r^{\nu}} f}{\partial z^{r^{\nu}}}=\frac{\partial^{r^{\nu}} f(z)}{\partial z_{1}^{r_{1}^{\nu}} \cdots \partial z_{n}^{r^{\nu} n_{\nu}}}
$$

with $r_{1}^{\nu}+\cdots+r_{n_{\nu}}^{\nu}=r^{\nu} \geqq 0$. Then by Theorem 1.2,

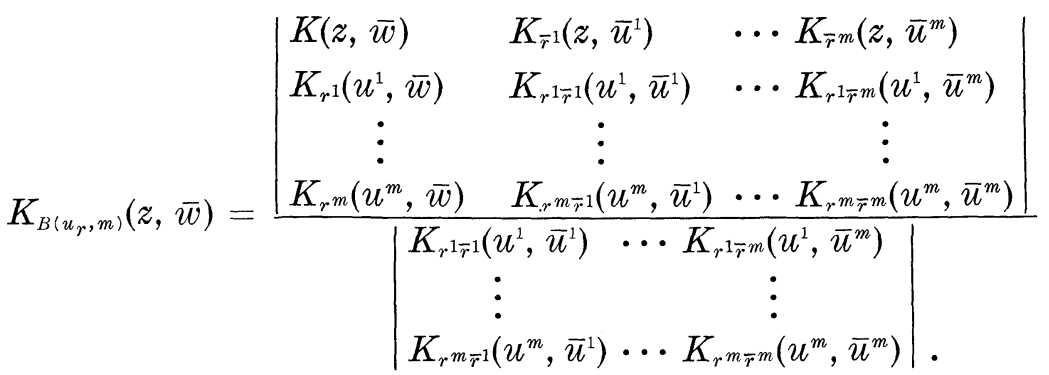

If $K_{B\left(u_{r}, \infty\right)}$ denotes the kernel function of

$$
H_{B}^{n} \cap\left[f_{r^{\nu}}\left(u^{\nu}\right)=0, u^{\nu} \in B, \nu=1,2, \cdots\right],
$$

then $K_{B\left(u_{r}, \infty\right)}(z, \bar{w})=\lim _{m \rightarrow \infty} K_{B\left(u_{r}, m\right)}(z, \bar{w})$, by Theorem 1.3 .

LEMMA 1.6. Let $z^{*}=z^{*}(z)$ be a pseudoconformal transformation of a domain $B$ onto a domain $B^{*}$ in $C^{n}$. Then any closed subspace $H K$ of $H_{B}^{n}$ is taken onto a closed subspace $H^{*} K^{*}$ of $H_{B^{*}}^{n}$ by the isometry $T$ given by $T f\left(z^{*}\right)=f\left(z\left(z^{*}\right)\right)\left((\partial z) /\left(\partial z^{*}\right)\right)$ and $K^{*}\left(z^{*}, \bar{w}^{*}\right)=$ $K(z, \bar{w})\left((\partial z) /\left(\partial z^{*}\right)\right)\left(\left(\overline{\partial w) /\left(\partial w^{*}\right.}\right)\right)$.

Proof. In [7] it was shown that if $T: H_{1} K_{1}\left(E_{1}\right) \rightarrow H_{2} K_{2}\left(E_{2}\right)$ is a (surjective) isometry, then $K_{2}(w, z)=T_{x}\left(\overline{T_{y}\left(K_{1}(y, x)\right)_{z}}\right)_{w}$.

As an immediate consequence of Lemma 1.6, we have

THEOREM 1.7. If $H_{1} K_{1}$ and $H_{2} K_{2}$ are any two closed subspaces of $H_{B}^{n}$, then $I\left(K_{1} ; K_{2} ; z, \bar{w}\right)=K_{1}(z, \bar{w}) / K_{2}(z, \bar{w})$ is a pseudoconformally invariant function. (That is, if $H_{i}^{*} K_{i}^{*}=T\left(H_{i} K_{i}\right), i=1,2$, where the isometry $T$ is induced by a pseudoconformal transformation from $B$ onto $B^{*}$, then $\left.K_{1}^{*}\left(z^{*}, \bar{w}^{*}\right) / K_{2}^{*}\left(z^{*}, \bar{w}^{*}\right)=K_{1}(z, \bar{w}) / K_{2}(z, \bar{w})\right)$.

Note 1.8. If $H_{i}$ is given as the intersection of the nullspaces of the linearly independent bounded linear functionals $\mathscr{L}^{i, m}, m=1,2, \cdots$, 
$i=1,2$, then we can write $I\left(\mathscr{L}^{1,1}, \mathscr{L}^{1,2}, \cdots ; \mathscr{L}^{2,1}, \mathscr{L}^{2,2}, \cdots ; z, \bar{w}\right)$ for $I\left(K_{1}, K_{2} ; z, \bar{w}\right)$, where $\mathscr{L} \in H K^{\circ} \rightarrow \mathscr{L}^{*} \in\left(H^{*} K^{*}\right)^{\circ}$ under the isometry $T$.

CoRollary 1.9. If $K$ denotes the Bergman kernel function of the space $H_{B}^{1}$, then

$$
J_{B}(z)=\frac{\left|\begin{array}{ll}
K(z, \bar{z}) & K_{\bar{z}}(z, \bar{z}) \\
K_{z}(z, \bar{z}) & K_{z \bar{z}}(z, \bar{z})
\end{array}\right|}{K^{3}(z, \bar{z})}
$$

is a scalar-valued conformal invariant.

Proof. By Theorem 1.7 and Note $1.8, I\left(D_{z} ; ; z, \bar{z}\right)$, where $D_{z} f=$ $f^{\prime}(z)$ in $H_{B}^{1}$, is a conformal invariant. But by Theorem 1.2,

$$
I\left(D_{z} ; ; z, \bar{z}\right)=\frac{\left|\begin{array}{ll}
K(z, \bar{z}) & K_{\bar{z}}(z, \bar{z}) \\
K_{z}(z, \bar{z}) & K_{z \bar{z}}(z, \bar{z})
\end{array}\right|}{\left[K_{z \bar{z}}(z, \bar{z}) K(z, \bar{z})\right]} .
$$

Now $D_{z} \in\left(H_{B}^{1}\right)^{\circ} \rightarrow D_{z^{*}}^{*} \in\left(H_{B^{*}}^{1}\right)^{\circ}$, where $z \rightarrow z^{*}$ and

$$
D_{z^{*}}^{*}(g)=g^{\prime}\left(z^{*}\right)\left(\frac{d z^{*}}{d z}\right)^{2}+g\left(z^{*}\right) \frac{d^{2} z^{*}}{d z^{2}} .
$$

This follows from the fact that if $g\left(z^{*}\right)=f\left(z\left(z^{*}\right)\right) d z / d z^{*}$, then $f(z)=$ $g\left(z^{*}(z)\right) d z^{*} / d z$ and $f^{\prime}(z)=g^{\prime}\left(z^{*}\right)\left(\left(d z^{*}\right) /(d z)\right)^{2}+g\left(z^{*}\right)\left(d^{2} z^{*}\right) /\left(d z^{2}\right)$. So $K(z, \bar{z})=$ $K^{*}\left(z^{*}, \overline{z^{*}}\right)\left(d z^{*}\right) /(d z)\left(\overline{d z^{*}}\right) /(d z)$,

$$
K_{z}(z, \bar{z})=D_{z^{*}}^{*} K^{*}\left(z^{*}, \overline{z^{*}}\right) \frac{\overline{d z^{*}}}{d z},
$$

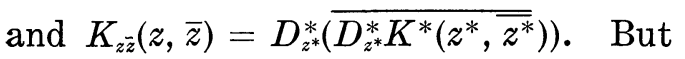

$$
\left|\begin{array}{l}
K^{*}\left(z^{*}, \overline{z^{*}}\right)\left|\frac{d z^{*}}{d z}\right|^{2} \overline{D_{z^{*}}^{*} K^{*}\left(z^{*}, \overline{z^{*}}\right)} \frac{d z^{*}}{d z} \\
D_{z^{*}}^{*} K^{*}\left(z^{*}, \overline{\left.z^{*}\right)} \frac{\overline{d z^{*}}}{d z} D_{z^{*}}^{*}\left(D_{z^{*}}^{*} K^{*}\left(z^{*}, \overline{z^{*}}\right)\right)\right.
\end{array}\right|=\left|\begin{array}{ll}
K^{*}\left(z^{*}, \overline{\left.z^{*}\right)}\right. & K_{\overline{z^{*}}}\left(z^{*}, \overline{z^{*}}\right) \\
K_{z^{*}}\left(z^{*}, \overline{\left.z^{*}\right)}\right. & K_{z^{*}, \overline{z *}}\left(z^{*}, \overline{\left.z^{*}\right)}\right.
\end{array}\right|\left|\frac{d z^{*}}{d z}\right|^{6} .
$$

Hence $I^{\prime}\left(D_{z} ; ; z, \bar{z}\right)=I\left(D_{z} ; ; z, \bar{z}\right) K_{z \bar{z}}(z, \bar{z}) / K^{2}(z, \bar{z})$ is a conformal invariant. Shows that $J_{B}(z)=J_{B^{*}}\left(z^{*}\right)$, i.e., $J_{B}(z)$ is a conformal invariant.

Similarly one obtains the following generalization of Corollary 1.9.

CoRollary 1.10. If $K$ denotes the Bergman kernel function of the space $H_{B}^{n}$, then 


$$
J_{B}(z)=J_{B}\left(z_{1}, \cdots, z_{n}\right)=\frac{\left|\begin{array}{cccc}
K(z, \bar{z}) & K_{\overline{z_{1}}}(z, \bar{z}) & \cdots & K_{\overline{z_{n}}}(z, \bar{z}) \\
K_{z_{1}}(z, \bar{z}) & K_{z_{1} \overline{z_{1}}}(z, \bar{z}) & \cdots & K_{z_{1} \overline{z_{n}}}(z, \bar{z}) \\
\vdots & \vdots & \vdots \\
K_{z_{n}}(z, \bar{z}) & K_{z_{n} \overline{z_{1}}}(z, \bar{x}) & \cdots & K_{z_{n} \bar{n}_{n}}(z, \bar{z})
\end{array}\right|}{K^{n+2}(z, \bar{z})}
$$

is a scalar-valued conformal invariant.

2. Minimum problems involving infinitely many side conditions.

THEOREM 2.1. If $\mathscr{L}^{m} \in H^{\circ}, m=1,2, \cdots$, are linearly independent, consider $\mu=\inf \|f\|$ under the side conditions $\mathscr{L}^{m}(f)=$ $a_{m}, m=1,2, \cdots$. Then the problem has a solution if and only if $\lim _{n \rightarrow \infty}\left\|f_{n}\right\|=M<\infty$, where $f_{n}$ yields inf $\|f\|$ under the side conditions $\mathscr{L}^{m}(f)=a_{m}, m=1,2, \cdots n$. Moreover, if a solution $f$ exists it is unique and is given by $f=\lim _{n \rightarrow \infty} f_{n}$, where $\|f\|=M$.

Proof. In [7] we showed that if $\mathscr{L}^{m} \sim L_{m}, m=1,2, \cdots, n$, then $f_{n}=-D_{a}^{L}(0) / D$, where $L=\left(L_{1}, \cdots, L_{n}\right)$ and $a=\left(a_{1}, \cdots, a_{n}\right)^{T}$.

If $\lim _{n \rightarrow \infty}\left\|f_{n}\right\|=M<\infty$, then

$$
\left\|f_{n}-f_{m}\right\|^{2}=\left\|f_{n}\right\|^{2}+\left\|f_{m}\right\|^{2}-2 \operatorname{Re}\left(f_{n}, f_{m}\right) .
$$

But if $m \geqq n$, we have that $\left(f_{n}, f_{m}\right)=\left\|f_{n}\right\|^{2}$, since $\left(f_{n}, f_{m}\right)$ is obtained by replacing the first row in the determinant form of $f_{n}$ by

$$
0\left(L_{1}, L_{m}\right) \cdots\left(L_{n}, f_{m}\right)=0 \overline{\mathscr{L}^{1}} f_{m} \cdots \overline{\mathscr{L}^{n}} f_{m}=0 \overline{a_{1}} \cdots \overline{a_{n}} .
$$

Thus $\left\|f_{n}-f_{m}\right\|^{2}=\left\|f_{m}\right\|^{2}-\left\|f_{n}\right\|^{2}$. So $\left\{f_{n}\right\}$ is a Cauchy sequence converging to $f \in H$ and $\|f\|=\lim _{n \rightarrow \infty}\left\|f_{n}\right\|=M$. Clearly $\mathscr{L}_{m} f=$ $\lim _{n \rightarrow \infty} \mathscr{L}^{m} f_{n}=a_{m}$. Suppose $\mathscr{L}^{m}(g)=a_{m}, \quad m=1,2, \ldots$ Consider $u=g-f$. Then $\mathscr{f}^{m}(u)=0, m=1,2, \cdots$, and thus

$(u, f)=\left(u, \lim _{n \rightarrow \infty} f_{n}\right)=\lim _{n \rightarrow \infty}\left(u, f_{n}\right)=\lim _{n \rightarrow \infty}\left(u, \sum_{k=1}^{n} c_{k}^{(n)} L_{k}\right)=\lim _{n \rightarrow \infty} \sum_{k=1}^{n} \overline{c_{k}^{(n)}} \mathscr{L}_{k} u=0$. Then $\|g\|^{2}=\|f\|^{2}+\|u\|^{2}$ and $\|g\| \geqq\|f\|$, while $\|g\|=\|f\| \Leftrightarrow u=$ $g-f=0$.

On the other hand if the problem has a solution $f$, then

$$
\left\|f_{1}\right\| \leqq \cdots \leqq\left\|f_{n}\right\| \leqq \cdots \leqq\|f\|<\infty,
$$

which implies that $\lim _{n \rightarrow \infty}\left\|f_{n}\right\|=M<\infty$. Then the argument above applies to show that in fact $f=\lim _{n \rightarrow \infty} f_{n}$ and so $\|f\|=M$. 
CoRollaly 2.2. If $H=H K$ in Theorem 2.1, then the solution is given by

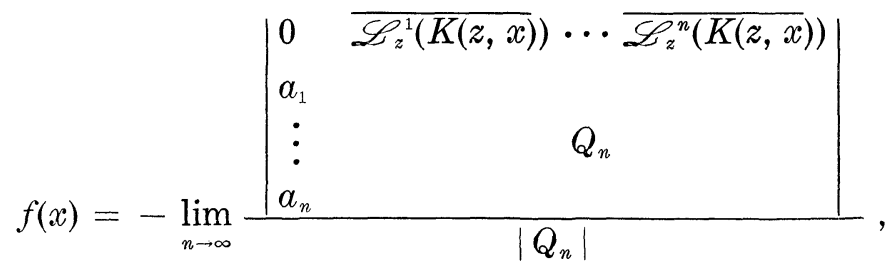

and

$$
\|f\|^{2}=-\lim _{n \rightarrow \infty} \frac{\left|\begin{array}{cc}
0 & \overline{a_{1}} \ldots \overline{a_{n}} \\
a_{1} & \\
\vdots & Q_{n} \\
a_{n} &
\end{array}\right|}{\left|Q_{n}\right|}
$$

where $Q_{n}^{*}=\left\{\mathscr{L}_{x}^{r}\left(\overline{\mathscr{L}_{z}^{s}(K(z, x)}\right)\right\}_{n \times n}$. Here the convergence is in the norm as well as being pointwise uniform on every set on which $K(x, x)$ is bounded.

Proof. Again, as in [7], if $\mathscr{L}^{m} \in H K^{\circ}, m=1, \cdots, n$, are linearly independent then $\mu=\inf \|f\|$ under the side conditions $\mathscr{L}^{m}(f)=a_{m}$, $m=1, \cdots, n$, has the unique solution $f(x)=-D_{a}^{x^{(x)}}(0) / D$ with $\mu^{2}=$ $-D_{a}^{\bar{a}}(0) / D$, where $\mathscr{L}(x)=\left(\mathscr{P}_{z}^{1}(K(z, x)), \cdots, \mathscr{P}_{z}^{n}(K(z, x))\right)$. The corollary then follows from Theorem 2.1 .

COROLlary 2.3. If $\mathscr{L}^{m} \in H K^{\circ}, m=1,2, \cdots$ are linearly independent, then there exists an $f$ in $H K$ such that $\mathscr{L}^{m}(f)=a_{m}$, $m=1,2, \cdots$, if and only if

$$
-\lim _{n \rightarrow \infty} \frac{\left|\begin{array}{cc}
0 & \overline{a_{1}} \cdots \overline{a_{n}} \\
a_{1} & \\
a_{n} & Q_{n}
\end{array}\right|}{\left|Q_{n}\right|}<\infty
$$

If a solution exists, the one of minimum norm is then given by formula (1).

Proof. There exists such a function $f$ if and only if there exists one of minimum finite norm in $H K$, and the statement follows from Corollary 2.2. 
COROLLARY 2.4. Let $\left\{z_{n}\right\}$ be any sequence of points in the ball $B=[|\boldsymbol{z}|<1] \subset C^{k}$, and let $\left\{w_{n}\right\}$ be any sequence of complex numbers. Then a necessary and sufficient condition that there exist a squareintegrable analytic function $f$ on $B$ such that $f\left(z_{n}\right)=w_{n}, n=1,2, \cdots$, is that

$$
\begin{aligned}
& a_{z}(w)=\alpha_{z_{1}, z_{2}}, \ldots\left(w_{1}, w_{2}, \cdots\right) \\
& =-\lim _{n \rightarrow \infty} \frac{\left|\begin{array}{ccc}
0 & \overline{w_{1}} & \cdots \overline{w_{n}} \\
w_{1} & \frac{1}{\left(1-z_{1} \cdot \overline{z_{1}}\right)^{k+1}} \cdots \frac{1}{\left(1-z_{1} \cdot \overline{z_{n}}\right)^{k+1}} \\
\vdots & \vdots & \vdots \\
w_{n} & \frac{1}{\left(1-z_{n} \cdot \overline{z_{1}}\right)^{k+1}} \cdots \frac{1}{\left(1-z_{n} \cdot \overline{z_{n}}\right)^{k+1}}
\end{array}\right|}{\left|\begin{array}{c}
\frac{1}{\left(1-z_{1} \cdot \overline{z_{1}}\right)^{k+1}} \cdots \frac{1}{\left(1-z_{1} \cdot \overline{z_{n}}\right)^{k+1}} \\
\vdots \\
\frac{1}{\left(1-z_{n} \cdot \overline{z_{1}}\right)^{k+1}} \cdots \frac{1}{\left(1-z_{n} \cdot \overline{z_{n}}\right)^{k+1}}
\end{array}\right|}<\infty,
\end{aligned}
$$

where if $z_{j}=\left(z_{j}^{1}, \cdots, z_{j}^{k}\right), \quad z_{i} \cdot \overline{z_{j}}=\sum_{r=1}^{k} z_{i}^{\overline{z_{j}^{r}}}$. If a solution exists, the solution $f(z)$ of minimum norm ${ }^{r=1}$ is obtained by replacing $\bar{w}_{j}$ by $k ! /\left(\pi^{k}\left(1-z \cdot \bar{z}_{j}\right)^{k+1}\right)$ in formula (2), and this convergence is in the norm and pointwise uniform on compact subsets of $B$.

Proof. The Hilbert space $H_{B}^{k}$ of all square-integrable analytic functions on $B$ has the Bergman kernel function $K(z, t)=k ! /\left(\pi^{k}\left(1-z \cdot \bar{t}^{k+1}\right)\right.$. Then $\left.\mathscr{S}_{x}^{r}\left(\overline{\mathscr{L}_{z}^{s}(K(z, x)}\right)\right)=K\left(z_{r}, z_{s}\right)=k ! /\left(\pi^{k}\left(1-z_{r} \cdot \bar{z}_{s}\right)^{k+1}\right)$, and the corollary follows from Corollary 2.3, and the fact that $K(z, z)$ is continuous on $B$.

Definition 2.5. A sequence of points $\left\{z_{n}\right\}$ in the ball $B=$ $[|z|<1] \subset C^{k}$ is called an $H-S$ interpolating sequence if for each sequence of complex numbers $w=\left\{w_{n}\right\} \in S$, there exists an $f \in H$ such that $f\left(z_{n}\right)=w_{n}$.

CoROLlaRY 2.6. $\left\{z_{n}\right\}$ is an $H_{B}^{k}-S$ interpolating sequence if and only if $a_{z}(w)$ is finite for each $w \in S$.

CoROLLARY 2.7. Let $\left\{z_{n}\right\}$ be any sequence of points in the unit disk $[|z|<1]$, and let $\left\{w_{n}\right\}$ be any sequence of complex numbers. Then a necessary and sufficient condition that there exist an analytic function $f$, with square integrable boundary values on the circle, such that $f\left(z_{n}\right)=w_{n}, n=1,2, \cdots$, is that 


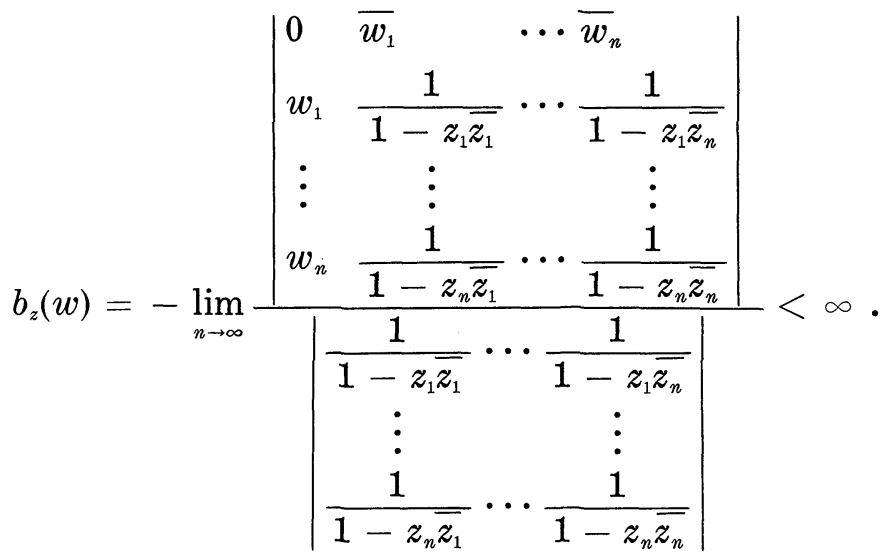

If a solution exists, the solution of minimum norm is obtained by replacing $\overline{w_{j}}$ by $1 /\left(2 \pi\left(1-z \overline{z_{j}}\right)\right)$ in formula (3), and this convergence is in the norm and pointwise uniform on compact subsets of $[|z|<1]$.

Proof. The kernel function of $H_{2}$ is the Szegö kernel $K(z, t)=$ $1 /(2 \pi(1-z \bar{t}))$ and the same argument applies as in Corollary 2.4.

COROLLARY 2.8. $\left\{z_{n}\right\}$ is an $H_{2}-S$ interpolating sequence if and only if $b_{z}(w)$ is finite for each $w \in S$.

\section{BIBLIOGRAPHY}

1. N. Aronszajn, Theory of reproducing kernels, Trans. Amer. Math. Soc. 68 (1950), 337-404.

2. S. Bergman, Über die Kernfunhtion eines Bereiches und ihr Verhalten am Rande, J. Reine Angew. Math. 169 (1933), 1-42, and 172 (1934), 89-128.

3 . _ Sur les fonctions orthogonales de plusiers variables complexes, Mém. des Sciences Math. 106 (1947).

4. - Sur la fonction-noyau d'un domaine et ses applications dans la théorie des transformations pseudo-conformes, Mém. des Sciences Math. 108 (1948).

5. - The kernel function and conformal mapping, Math. Surveys 5, Amer. Math. Soc., New York, 1950.

6. — Distinguished sets of invariants in the theory of pseudo-conformal transformations, J. D'Analyse Math. 13, Jerusalem, 1964.

7. B. Chalmers, Linear transformations in Hilbert Spaces with kernel function (to appear)

8. P. J. Davis, Interpolation and approximation, Blaisdell, 1963.

9. B. Epstein, Orthogonal families of analytic functions, New York, 1964.

10. K. Hoffman, Banach Spaces of analytic functions, Prentice-Hall New Jersey, 1962.

11. H. Meschkowski, Hilbertsche Raume mit Kernfunktion, Berlin, 1962.

12. H. S. Shapiro and A. L. Shields, On some interpolation problems for analytic functions, Amer. J. Math. (1961), 513-532. 
13. G. Springer, Pseudo-conformal transformations onto circular domains, Duke Math. J. 18 (1951), 411-424.

Received April 3, 1969.

University of CALifornia, Riverside 


\title{
PACIFIC JOURNAL OF MATHEMATICS
}

\author{
EDITORS
}

\author{
H. ROYDEN \\ Stanford University \\ Stanford, California \\ RICHARD PIERCE \\ University of Washington \\ Seattle, Washington 98105
}

\author{
J. DUGUNDJI \\ Department of Mathematics \\ University of Southern California \\ Los Angeles, California 90007 \\ BASIL GORDON \\ University of California \\ Los Angeles, California 90024
}

\section{ASSOCIATE EDITORS}

E. F. BECKENBACH
B. H. NeumanN

F. WOLF
K. YoshidA

\section{SUPPORTING INSTITUTIONS}

\author{
UNIVERSITY OF BRITISH COLUMBIA \\ CALIFORNIA INSTITUTE OF TECHNOLOGY \\ UNIVERSITY OF CALIFORNIA \\ MONTANA STATE UNIVERSITY \\ UNIVERSITY OF NEVADA \\ NEW MEXICO STATE UNIVERSITY \\ OREGON STATE UNIVERSITY \\ UNIVERSITY OF OREGON \\ OSAKA UNIVERSITY \\ UNIVERSITY OF SOUTHERN CALIFORNIA
}

\author{
STANFORD UNIVERSITY \\ UNIVERSITY OF TOKYO \\ UNIVERSITY OF UTAH \\ WASHINGTON STATE UNIVERSITY \\ UNIVERSITY OF WASHINGTON

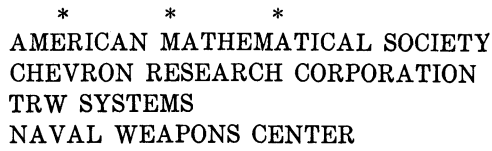

The Supporting Institutions listed above contribute to the cost of publication of this Journal, but they are not owners or publishers and have no responsibility for its content or policies.

Mathematical papers intended for publication in the Pacific Journal of Mathematics should be in typed form or offset-reproduced, double spaced with large margins. Underline Greek letters in red, German in green, and script in blue. The first paragraph or two must be capable of being used separately as a synopsis of the entire paper. It should not contain references to the bibliography. Manuscripts, in duplicate if possible, may be sent to any one of the four editors. Please classify according to the scheme of Math. Rev. 36, 1539-1546. All other communications to the editors should be addressed to the managing editor, Richard Arens, University of California, Los Angeles, California, 90024.

50 reprints are provided free for each article; additional copies may be obtained at cost in multiples of 50 .

The Pacific Journal of Mathematics is published monthly. Effective with Volume 16 the price per volume (3 numbers) is $\$ 8.00$; single issues, $\$ 3.00$. Special price for current issues to individual faculty members of supporting institutions and to individual members of the American Mathematical Society: $\$ 4.00$ per volume; single issues $\$ 1.50$. Back numbers are available.

Subscriptions, orders for back numbers, and changes of address should be sent to Pacific Journal of Mathematics, 103 Highland Boulevard, Berkeley, California, 94708.

PUBLISHED BY PACIFIC JOURNAL OF MATHEMATICS, A NON-PROFIT CORPORATION

Printed at Kokusai Bunken Insatsusha (International Academic Printing Co., Ltd.), 7-17, Fujimi 2-chome, Chiyoda-ku, Tokyo, Japan. 


\section{Pacific Journal of Mathematics}

\section{Vol. 31, No. $3 \quad$ BadMonth, 1969}

George E. Andrews, On a calculus of partition functions .................. 555

Silvio Aurora, A representation theorem for certain connected rings ............ 563

Lawrence Wasson Baggett, A note on groups with finite dual spaces ............. 569

Steven Barry Bank, On majorants for solutions of algebraic differential equations in regions of the complex plane ............................... 573

Klaus R. Bichteler, Locally compact topologies on a group and the corresponding continuous irreducible representations ......................... 583

Mario Borelli, Affine complements of divisors ....................... 595

Carlos Jorge Do Rego Borges, A study of absolute extensor spaces ............. 609

Bruce Langworthy Chalmers, Subspace kernels and minimum problems in Hilbert

spaces with kernel function ...................................... 619

John Dauns, Representation of L-groups and F-rings................. 629

Spencer Ernest Dickson and Kent Ralph Fuller, Algebras for which every

indecomposable right module is invariant in its injective envelope ...........

Robert Fraser and Sam Bernard Nadler, Jr., Sequences of contractive maps and fixed

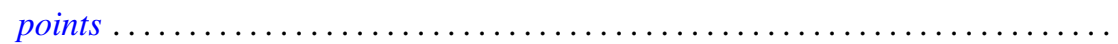

Judith Lee Gersting, A rate of growth criterion for universality of regressive

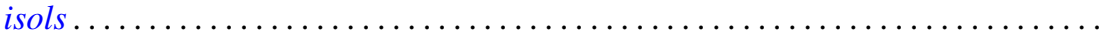

Robert Fred Gordon, Rings in which minimal left ideals are projective ............

Fred Gross, Entire functions of several variables with algebraic derivatives at certain algebraic points

W. Charles (Wilbur) Holland Jr. and Stephen H. McCleary, Wreath products of ordered permutation groups .........................

W. J. Kim, The Schwarzian derivative and multivalence .................. 717

Robert Hamor La Grange, Jr., On $(\mathrm{m}-\mathrm{n})$ products of Boolean algebras ......... 725

Charles D. Masiello, The average of a gauge ........................ 733

Stephen H. McCleary, The closed prime subgroups of certain ordered permutation

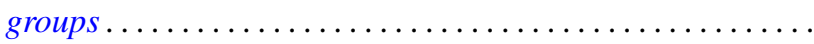

Richard Roy Miller, Gleason parts and Choquet boundary points in convolution measure algebras ...............................

Harold L. Peterson, Jr., On dyadic subspaces ........................ 773

Derek J. S. Robinson, Groups which are minimal with respect to normality being intransitive........................................... 777

Ralph Edwin Showalter, Partial differential equations of Sobolev-Galpern type . . . 787

David Slepian, The content of some extreme simplexes ................... 795

Joseph L. Taylor, Noncommutative convolution measure algebras ............. 809

B. S. Yadav, Contractions of functions and their Fourier series ............... 827

Lindsay Nathan Childs and Frank Rimi DeMeyer, Correction to automorphisms of separable algebras" ....................... 833

Moses Glasner and Richard Emanuel Katz, Correction to: "Function-theoretic degeneracy criteria for Riemannian manifolds".............

Satish Shirali, Correction to: "On the Jordan structure of complex Banach

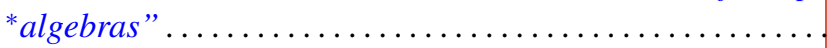

